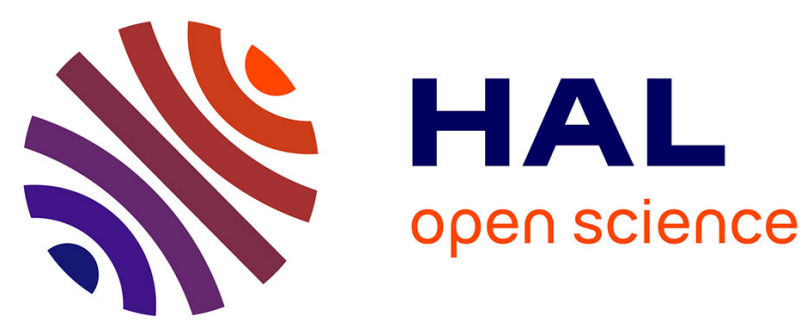

\title{
Re: Cardiotoxicity of immune checkpoint inhibitors: A systematic review and meta-analysis of randomised clinical trials
}

\author{
Joe-Elie Salem, Stephane Ederhy, Agnès Dechartres
}

\section{To cite this version:}

Joe-Elie Salem, Stephane Ederhy, Agnès Dechartres. Re: Cardiotoxicity of immune checkpoint inhibitors: A systematic review and meta-analysis of randomised clinical trials. European Journal of Cancer, 2021, 155, pp.299-302. 10.1016/j.ejca.2021.05.017 . hal-03471241

\section{HAL Id: hal-03471241 \\ https://hal.sorbonne-universite.fr/hal-03471241}

Submitted on 8 Dec 2021

HAL is a multi-disciplinary open access archive for the deposit and dissemination of scientific research documents, whether they are published or not. The documents may come from teaching and research institutions in France or abroad, or from public or private research centers.
L'archive ouverte pluridisciplinaire HAL, est destinée au dépôt et à la diffusion de documents scientifiques de niveau recherche, publiés ou non, émanant des établissements d'enseignement et de recherche français ou étrangers, des laboratoires publics ou privés. 


\title{
Answer to Cardiotoxicity of immune checkpoint inhibitors: A systematic review and meta-analysis of randomised clinical trials - An enigmatic discordance resolved
}

\author{
Joe-Elie SALEM, MD, PhD; Stephane EDERHY, MD²; Agnès DECHARTRES, MD, PhD³
}

Correspondence: Joe-Elie Salem, M.D., Ph.D, Centre d'Investigation Clinique Paris-Est, Hôpital PitiéSalpêtrière, Bâtiment Antonin Gosset, 47-83 Bld de I'hôpital, 75013 Paris, France. Secretariat: +33 142 1785 31, Fax: +33 1421785 32; Email: joe-elie.salem@aphp.fr

${ }^{1}$ Sorbonne Université, INSERM, AP-HP, Pitié-Salpêtrière Hospital, Department of Pharmacology, CIC1901; Sorbonne Université, INSERM, APHP.Sorbonne UNICO-GRECO Cardio-oncology Program, F-75013 Paris, France.

${ }^{2}$ Sorbonne Université, INSERM, AP-HP, Saint-Antoine Hospital, Department of Cardiology, CIC-1901; APHP.Sorbonne UNICO-GRECO Cardio-oncology Program, F-75013 Paris, France.

${ }^{3}$ Sorbonne Université, INSERM, Institut Pierre Louis d'Epidémiologie et de Santé Publique, UMR-S 1136, AP-HP, Hôpital Pitié-Salpêtrière, Département de Santé Publique, Paris, France

$968 / 1000$ words

$10 / 10$ references

1 Figure

Disclosures: None 
Immune-checkpoint inhibitors $(\mathrm{ICl})$ are revolutionary anticancer drugs approved in an expanding variety of cancer types. ${ }^{1} \mathrm{ICl}$ restore the activity of the immune system and primarily of T-cells to destroy neoplastic cells. ${ }^{1}$ Currently, approved $\mathrm{ICl}$ are monoclonal antibodies blocking CTLA4 (cytotoxic Tlymphocyte associated protein 4) and PD1 (Programmed cell Death protein 1), which are immunecheckpoint brakes expressed on the T-cells. ${ }^{1} \mathrm{ICl}$ also include anti-PDL1 (PD1 ligand located on cancer cells) normally interacting with PD1 to tone-down T-cells. ${ }^{1}$ Though, ICI may induce immune-related adverse events (irAE) with auto-immune reaction targeting potentially any organ and eventually being fatal in 0.5-1\% of ICl treated patients. ${ }^{2}$ IrAE, when symptomatic, are generally treated by withholding $\mathrm{ICl}$ and start of immunosuppressants including glucocorticoids in the first place. ${ }^{2}$ IrAE affecting the cardiovascular system mainly includes myocarditis, pericarditis, arrhythmias and vasculitis. ${ }^{3}$ Myocarditis is fortunately a rare event but is the top life-threatening irAE with fatality rates reaching up to $50 \%$ in the first cohorts reported. ${ }^{3}$ Johnson et al. first described two fatal ICI-myocarditis cases with on autopsy, activated T-cells and macrophages leading to heart and peripheral muscles necrosis, providing the main pathophysiological processes of this novel condition. ${ }^{4}$ Incidence of myocarditis have been estimated around $0.03 \%$ in first clinical trials evaluating $\mathrm{ICl}$ monotherapies and up to $1 \%$ in real-life cohorts involving aware medical teams including oncologists and cardiologists. ${ }^{3,4}$ But, with the increased use of $\mathrm{ICl}$ and the multiplication of cancer indications, numbers of deadly and glucocorticoids-resistant ICI-myocarditis have exploded, representing an important concern for clinicians and regulatory institutions. ${ }^{5-7}$ Combination of $\mathrm{ICl}$, including an anti-CTLA4 and anti-PD1, have been repeatedly shown to be a risk factor for ICI-myocarditis using multiple study designs..$^{3,4,8}$ First, an analysis of Bristol-Myers Squibb corporate safety databases as of April 2016 showed a significantly higher incidence of myocarditis in patients who received combination therapy (an anti-PD1 and an anti-CTLA4; 8/2,974 (0.27\%)) than in those who received an anti-PD1 alone $\left(10 / 17,620\right.$ (0.06\%); P<0.001). ${ }^{4}$ Second, in a query of VigiBase, the WHO pharmacovigilance database, IClmyocarditis was overreported in patients treated with $\mathrm{ICl}$ combination therapy versus those treated with monotherapy (Reporting odds-Ratio=4.31[2.86-6.38]). ${ }^{3}$ Thirdly, in an U.S. Food and Drug Administration 
pooled analysis of 59 trials $(\mathrm{N}=21,664), \mathrm{ICl}$ therapy was associated with higher rates of myocarditis, vasculitis, ischemia, arrhythmia, and pericardial disease compared to non-ICI therapy. ${ }^{7}$ When $\mathrm{ICI}$ were used in combination $(\mathrm{N}=1,533)$, cardiovascular adverse events increased across most categories compared to $\mathrm{ICl}$ monotherapy $(\mathrm{N}=17,072)$, and particularly myocarditis $(0.13 \%$ vs. $0.02 \%$; Relativerisk=7.42). ${ }^{7}$ Lastly, in preclinical models, the deleterious interaction between PD1 and CTLA4 was further confirmed. Wei et al identified a dose-dependent genetic and functional interaction between the T cellnegative costimulatory genes Ctla4 and Pdcd1, which manifests as fatal myocarditis in $\mathrm{Ctla}^{+/-} \mathrm{Pdcd}^{-/-}$ mice contrasting with absence of this phenotype in $\mathrm{Ctla}_{4}^{+/+} \mathrm{Pdcd}^{-/-}$or $\mathrm{Ctla}^{+/-} \mathrm{Pdcd}^{+/-}$mice ${ }^{8}$ In this context, results of the systematic review and meta-analysis of randomized clinical trials by Agostinetto et al, showing no association between $\mathrm{ICl}$ monotherapies, or even $\mathrm{ICl}$ combination therapies compared to non- $\mathrm{ICl}$ controls patients stands out remarkably. ${ }^{9}$ Herein, we investigated the reason of such discordant findings.

Since ICI-myocarditis are rare events, many ICI trials did not report any such events in either ICl and non$\mathrm{ICl}$ arms and these trials should not have been included in meta-analysis. Indeed, the Cochrane handbook (the well-recognized reference for conducting systematic reviews and meta-analyses, www.training.cochrane.org/handbook) specifically states that for studies with no events in either arm (\#section-10-4-4-2), the standard practice in meta-analysis of odds ratios and risk ratios is to exclude such studies. "This is because such studies do not provide any indication of either the direction or magnitude of the relative treatment effect. Whilst it may be clear that events are very rare on both the experimental intervention and the comparator intervention, no information is provided as to which group is likely to have the higher risk, or on whether the risks are of the same or different orders of magnitude (when risks are very low, they are compatible with very large or very small ratios). Whilst one might be tempted to infer that the risk would be lowest in the group with the larger sample size (as the upper limit of the confidence interval would be lower), this is not justified as the sample size allocation was determined by the study investigators and is not a measure of the incidence of the event. Bradburn and colleagues 
undertook simulation studies which revealed that all risk difference methods yield confidence intervals that are too wide when events are rare, and have associated poor statistical power, which make them unsuitable for meta-analysis of rare events (Bradburn et al 2007). This is especially relevant when outcomes that focus on treatment safety are being studied, as the ability to identify correctly (or attempt to refute) serious adverse events is a key issue in drug development. Furthermore, it is likely that outcomes for which no events occur in either arm may not be mentioned in reports of many randomized trials, precluding their inclusion in a meta-analysis". This recommendation was not respected in the metaanalysis by Agostinetto et al, leading as expected to falsely negative results. ${ }^{9}$ When reperforming the meta-analysis after removing the trials with no events in $\mathrm{ICl}$ and non- $\mathrm{ICl}$ arms, and keeping the same events data extracted, ${ }^{9}$ results are much different and confirm the well-consolidated association between $\mathrm{ICl}$ and myocarditis (Risk-ratio 2.3-2.7, with significance depending on type of model used (fixed or random effects models) and possible correction methods for $\mathrm{ICl}$ monotherapies vs. non-ICl groups in Figure-1). Lastly, Agostinetto et al. only extracted the adverse events data from publications whereas results posted at ClinicalTrials.gov especially adverse events and serious adverse events are generally more completely reported. ${ }^{10}$ Therefore, reperforming a more comprehensive meta-analysis with methods adapted to rare events and search of clinical trial registers as ClinicalTrials.gov might be desirable to further assess cardiovascular toxicities spectrum induced by ICI. 


\section{REFERENCES}

1. Geraud A, Gougis P, Vozy A, et al. Clinical Pharmacology and Interplay of Immune Checkpoint Agents: A Yin-Yang Balance. Annu Rev Pharmacol Toxicol 2020.

2. Wang DY, Salem JE, Cohen JV, et al. Fatal Toxic Effects Associated With Immune Checkpoint Inhibitors: A Systematic Review and Meta-analysis. JAMA Oncol 2018; 4(12): 1721-8.

3. Salem J-E, Manouchehri A, Moey M, et al. Cardiovascular toxicities associated with immune checkpoint inhibitors: an observational, retrospective, pharmacovigilance study. The Lancet Oncology 2018; 19(12): 1579-89.

4. Johnson DB, Balko JM, Compton ML, et al. Fulminant Myocarditis with Combination Immune Checkpoint Blockade. N Engl J Med 2016; 375(18): 1749-55.

5. Salem JE, Allenbach Y, Vozy A, et al. Abatacept for Severe Immune Checkpoint InhibitorAssociated Myocarditis. N Engl J Med 2019; 380(24): 2377-9.

6. Moslehi JJ, Salem JE, Sosman JA, Lebrun-Vignes B, Johnson DB. Increased reporting of fatal immune checkpoint inhibitor-associated myocarditis. Lancet 2018; 391(10124): 933.

7. Amiri-Kordestani L, Moslehi J, Cheng J, et al. Cardiovascular adverse events in immune checkpoint inhibitor clinical trials: A U.S. Food and Drug Administration pooled analysis. Journal of Clinical Oncology 2018; 36(15_suppl): 3009-.

8. Wei SC, Meijers WC, Axelrod ML, et al. A genetic mouse model recapitulates immune checkpoint inhibitor-associated myocarditis and supports a mechanism-based therapeutic intervention. Cancer Discov 2020.

9. Agostinetto $E$, Eiger $D$, Lambertini $M$, et al. Cardiotoxicity of immune checkpoint inhibitors: A systematic review and meta-analysis of randomised clinical trials. Eur J Cancer 2021; 148: 76-91.

10. Riveros C, Dechartres A, Perrodeau E, Haneef R, Boutron I, Ravaud P. Timing and completeness of trial results posted at ClinicalTrials.gov and published in journals. PLoS Med 2013; 10(12): e1001566; discussion e. 
Figure. Forest-plot for myocarditis events in single immune checkpoint inhibitors group (ICI) versus non$\mathrm{ICl}$ group. Meta-analysis was performed after adding 0.5 cell only to studies with no event in one of the two compared groups ( $\mathrm{ICl}$ vs. non-ICl) but after excluding the studies with no event in both groups (A); and using the correction proposed by Sweeting applying the reciprocal of the opposite arm size (B).

A

Study or

Subgroup

Subgroup $=$ Anti-CTLA4

EORTC-18071, 2016

Total (fixed effect, $95 \% \mathrm{CI}$ )

Total (random effects, $95 \% \mathrm{Cl}$ )

Heterogeneity: not applicable

Subgroup $=$ Anti-PD $(L) 1$

JAVELIN Lung 200, 2018

JAVELIN Renal 101, 2019

KEYNOTE-042, 2019

KEYNOTE-048, 2019

KEYNOTE-181, 2019

KEYNOTE-189, 2020

KEYNOTE-426, 2019

KEYNOTE-522, 2020

NCT02362594, 2018

NCT03051659, 2019

PACIFIC, 2017

Total (fixed effect, 95\% CI)

Total (random effects, $95 \% \mathrm{Cl}$ )

Heterogeneity: $\mathrm{Tau}^{2}=0 ; \mathrm{Chi}^{2}=3.48, \mathrm{df}=10(\mathrm{P}=0.97) ; \mathrm{I}^{2}=0 \%$

Total (fixed effect, $95 \% \mathrm{Cl}$ )

5467

$\begin{array}{ll}1 & 393 \\ 1 & 434\end{array}$

1636

1576

1314

1405

$\begin{array}{ll}2 & 429\end{array}$

$\begin{array}{ll}5 & 781 \\ 1 & 509\end{array}$

$\begin{array}{rr}1 & 44 \\ 0 & 475\end{array}$

4996

ICl NON-ICl Weight Weight

Risk Ratio

Risk Ratio

Total (random effects, $\mathbf{9 5} \% \mathrm{Cl}$ )

Heterogeneity: $\operatorname{Tau}^{2}=0 ; \mathrm{Chi}^{2}=3.50, \mathrm{df}=11(\mathrm{P}=0.98) ; I^{2}=0 \%$

$4272100.0 \%$

$\begin{array}{lr}-- & - \\ - & 100.0 \%\end{array}$

$2.34[1.02 ; 5.40]$

$2.32[0.93 ; 5.77]$

$2.79[0.11 ; 68.19]$

$3.03[0.12 ; 74.29]$

$2.90[0.12 ; 71.08]$

$1.50[0.06 ; 36.61]$

$2.83[0.12 ; 69.15]$

$1.50[0.06 ; 36.61]$

$4.95[0.24 ; 102.87]$

$5.48[0.30 ; 98.89]$

$2.96[0.12 ; 72.46]$

$3.00[0.13 ; 71.67]$

$0.16[0.01 ; 4.02]$

$2.30[0.97 ; 5.46]$

$2.27[0.88 ; 5.86]$

$91.9 \%$
$3.02[0.12 ; 73.92]$

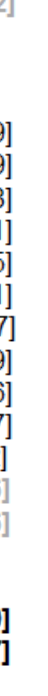

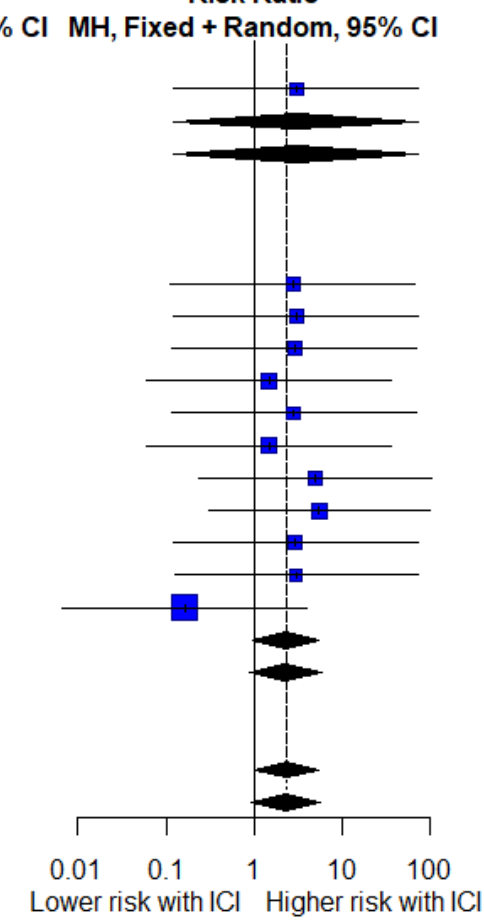

B

Study or

Subgroup

Subgroup = Anti-CTLA4

ICI

NON-ICl Weight Weight

Risk Ratio

Risk Ratio

Events Total Events Tota

EORTC-18071, 2016

Total (fixed effect, $95 \% \mathrm{Cl}$ )

Total (random effects, $95 \% \mathrm{CI}$ )

Heterogeneity: not applicable

Subgroup $=$ Anti-PD(L)1

JAVELIN Lung 200, 2018

JAVELIN Renal 101, 2019

KEYNOTE-042, 2019

KEYNOTE-048, 2019

KEYNOTE-181, 2019

KEYNOTE-189, 2020

KEYNOTE-426, 2019

KEYNOTE-522, 2020

NCT02362594, 2018

NCT03051659, 2019

PACIFIC, 2017

Total (fixed effect, 95\% CI)

Total (random effects, $95 \% \mathrm{Cl}$ )

Heterogeneity: $\operatorname{Tau}^{2}=0 ; \mathrm{Chi}^{2}=3.14, \mathrm{df}=10(\mathrm{P}=0.98) ; \mathrm{I}^{2}=0 \%$

Total (fixed effect, $95 \% \mathrm{Cl}$ )

1471

$0 \quad 474$

$7.0 \%$

$8.7 \%$

$8.7 \%$

$3.01[0.12 ; 73.36]$

$3.01[0.12 ; 73.36]$

$3.01[0.12 ; 73.36]$

Total (random effects, $95 \% \mathrm{Cl}$ )

Heterogeneity: $\mathrm{Tau}^{2}=0 ; \mathrm{Chi}^{2}=3.15, \mathrm{df}=11(\mathrm{P}=0.99) ; \mathrm{I}^{2}=0 \%$
5467

$\begin{array}{lllll}1 & 393 & 0 & 365 & 7.0 \%\end{array}$

$\begin{array}{lllll}1 & 434 & 0 & 439 & 7.0 \%\end{array}$

$\begin{array}{lllll}1 & 636 & 0 & 615 & 7.0 \%\end{array}$

1576

1314

1405

$\begin{array}{ll}0 & 287\end{array}$

$\begin{array}{ll}0 & 296\end{array}$

$0 \quad 202$

$\begin{array}{ll}2 & 429\end{array}$

5781

1509

144

$0 \quad 475$

4996

$0 \quad 425$

$\begin{array}{ll}0 & 389\end{array}$

$\begin{array}{ll}0 & 502\end{array}$

$\begin{array}{lll}1 & 234 & 25.1 \%\end{array}$

$3798 \quad 93.0 \%$

$8.4 \%$

$8.7 \%$

$8.5 \%$

$6.4 \%$

$8.5 \%$

$6.4 \%$

$9.6 \%$

$7.2 \%$

$8.6 \%$

$8.8 \%$

$10.3 \%$

$91.3 \%$

$4272100.0 \%$

$-$

$100.0 \%$
$2.93[0.11 ; 74.66]$

3.01 [0.12; 73.28]

$2.97[0.12 ; 74.03]$

$2.50[0.06 ; 103.04]$

$2.94[0.12 ; 74.33]$

$2.50[0.06 ; 102.84]$

$4.98[0.24 ; 104.04]$

$8.49[0.26 ; 279.84]$

$2.99[0.12 ; 73.68]$

$3.00[0.13 ; 71.67]$

$0.25[0.01 ; 4.66]$

$2.70[1.08 ; 6.72]$

$2.52[0.94 ; 6.73]$

2.72 [1.13; 6.54]

$2.56[1.00 ; 6.54]$ 